\title{
Social Determinants and Health Literacy of the Elderly: Walk to Well-Being
}

\author{
Cristina Vaz de Almeida ${ }^{1}$, Ana Veiga ${ }^{2}$ \\ ${ }^{1}$ ISPA, Lisbon, Portugal \\ ${ }^{2}$ ESEL, Lisbon, Portugal \\ Email: cristina.vazalmeida@scml.pt
}

How to cite this paper: de Almeida, C.V. and Veiga, A. (2020) Social Determinants and Health Literacy of the Elderly: Walk to Well-Being. Open Access Library Journal, 7: e6390.

https://doi.org/10.4236/oalib.1106390

Received: May 1, 2020

Accepted: June 7, 2020

Published: June 10, 2020

Copyright $\odot 2020$ by author(s) and Open Access Library Inc.

This work is licensed under the Creative Commons Attribution International License (CC BY 4.0).

http://creativecommons.org/licenses/by/4.0/

(c) (i) Open Access

\begin{abstract}
Framework: Research on health determinants reports that health literacy has a significant impact on the quality of life and well-being of individuals (Kottke, Stiefel \& Pronk, 2016) organizations (Brach et al., 2012) and communities (when societies go through adverse conditions, for example through an economic, financial crisis, or even the crisis "COVID-19" whose consequences are still to be determined in the effects on the quality of life of individuals. Health literacy is considered as one of the resources that play an important role in increasing individual resilience and well-being and also a result of health promotion actions such as education, social mobilization and advocacy, through the defense of citizens' interests (Nutbeam, 2000). Well-being is a positive concept (Kottke, Stiefel \& Pronk, 2016). Methodology: In a quantitative and qualitative approach, a descriptive cross-sectional study was developed to a group of 22 elderly people, who attend a Day Center in the geographical area of Lisbon (Portugal). Data were collected using the HLS-EUPT questionnaire, the sociodemographic questionnaire with the selected sample-a group of elderly-as well as semi-structured interviews with caregivers involved in this context. An evaluation was also made by observing manifestations of well-being among the individuals in the sample. Results: The results show a population with low health literacy, with chronic disease, but whose support of the social organization where they spent their time, the easy access arranged by the social organization with private transportation and food and the social activities they develop daily which stimulate a daily relationship with other persons, are strong factors that promote well-being. It is therefore pointed out a need to fit social organizations within the investments of health literacy promoters of "literate organizations" (Brach et al., 2012), since it is in these organizations that a large part of the older population in Portugal is daily in contact and therefore in close proximity to interventions favorable to improve their health literacy.
\end{abstract}




\section{Subject Areas}

Health Policy, Public Health, Sociology

\section{Keywords}

Health Literacy, Elder, Social Organizations, Health-Communication, Well-Being

\section{Introduction}

\subsection{Autonomy, Empowerment and Quality of Life}

It is through greater personal and autonomy, empowerment in health-related decision-making, as well as involvement in a wide range of health conditions [1] that individuals become active [2], control their health, recognize their potential, adapt and achieve the stability of their experiences that allow them greater wellbeing [6], in addition to the physiological conditions of their health [3].

The activation of the patient occurs with the increase of knowledge, skills, confidence and behaviors necessary to manage his own health and health care [2].

It is evident that the mere delivery of information is insufficient to activate the patient's behavior [4] [5]. But the words we use influence our thinking ([6], p. 2).

Therefore, through words, the individual's motivation to do more for him and for those who depend on them, and in a more effective way, can be enhanced, empowering him to defend and maintain better health.

And, this empowerment is a fundamental dimension of health literacy [7] [8], which includes both health-promoting behavior, as well as the ability to perform primary care, self-care and family and, in some cases, even first aid [9]. Empowerment encompasses knowledge about when a person should enter the health system and how to navigate through its complexity. It means understanding health professionals' advice and instructions and actively participating with them in the treatment decision process. And, in fact, health literacy is active and the individual is able to access, evaluate, understand and use [10] this global health system that comes to him in different ways-knowledge or cognition [8] [11], emotions and feelings [12] and which applies to the various health realities, through verbal and non-verbal communication decoding each input related to "health" [13] according to its socio-economic, political and cultural context [1].

\subsection{Quality of Life Means Well-Being?}

Quality of life is a broad concept, which integrates people's perception of their position in life in the context of the culture and value systems in which they live. For quality of life, people also consider their goals, expectations, standards and concerns, physical health, psychological status, level of independence, social relationships, personal beliefs and their relationship with the environment in which they operate ([14], p. 25). 
According to Kottke, Stiefel and Pronk [6], the association of the word "health" with "health care" is so strong that it creates a fusion of "health care policy" with "health policy" that it is sometimes impossible to break.

Paasche-Orlow and Wolf [15] associate health literacy, memory and navigation in the health system, in physiological components such as hearing and verbal fluency, and show their impact on health outcomes, namely: 1) on skills navigation, 2) self-efficacy; 3) barriers and perceived beliefs, which negatively influence access to and use of health care; 4) knowledge, 5) participation in decision making, which influences professional-patient interactions; 6) motivation, 7) problem solving, 8) knowledge and skills that influence self-care.

The Ad Hoc Committee [16] explained that people with low literacy and chronic illnesses are less able to take care of themselves, making more use of health services.

Specifically, for older people, WHO [17] recommends introducing effective and coherent intersectoral actions to combat inequities, to prevent and manage the development of chronic diseases and to improve survival and well-being across the social gradient.

\subsection{The Social Determinants of Health}

According to the WHO [17], the social determinants of health in the European Region imply, among others, the following reflections and interventions: It is necessary to avoid the perpetuation in the life cycle, of inequities and health risks that pass from one generation to another. In this sense, WHO [17] recommends the guarantee of conditions for the quality of parents and the construction of the family, the promotion of gender equity and adequate social and health protection.

It is observable and proven the degradation of the quality of life and well-being of people at risk and socially vulnerable. This quality of life also ends up being affected by the decrease of available resources to face the requests and needs that the various sectors of society are facing in a crisis. The social state is obliged to make a complex management of expectations that involve, in addition to the central governmental powers, naturally, the municipalities, organizations of a social nature or social solidarity.

Regarding local communities, the WHO recommendation [17] defends joint efforts to reduce inequities in local health determinants, through co-creation and partnership with those affected, civil society and a set of civic partners.

As for the process of social exclusion, vulnerability and disadvantage that many people find themselves in, WHO [17] encourages them to act in the development of systems and processes within more sustainable, cohesive and inclusive societies, focusing on the groups most severely affected by exclusive processes.

In a perspective of sustainable development and health recommendation, WHO [17] also defends long-term planning and safeguarding the interests of future generations, identifying the links between environmental, social and economic factors and their centrality with policies and practices. 
Thus, public policies also suffer from pressure, continually adjusting themselves to face their "public" end of maintaining and restoring the health of their citizens. In this health report, the weight of "well-being" is accentuated.

\section{Methodology}

In a quantitative and qualitative approach, a cross-sectional descriptive study was developed with a group of 22 elderly people, who attend a Day Center in the geographical area of Lisbon (Portugal.) The data were collected using the HLSEU-PT questionnaire, as well as semi-structured interviews with the caregivers involved in this context. The sample was based on a selection by convenience defined in concrete by the elderly enrolled in the Day Center, who were present on the days (one week) stipulated for the application of the questionnaires.

We established as inclusion criteria the acceptance to participate in the project and exclusion for users diagnosed with or condition that could interfere with data collection. Compliance with ethical procedures was ensured throughout the process, and the necessary authorizations were obtained: 1) the application of the European Health Literacy Questionnaire Health Literacy Survey in Portuguese (HLS-EU-PT), translated and validated for the Portuguese population, 2) the Management of this Social Organization. This questionnaire consists of forty-seven questions aimed at assessing the general health literacy index. In these questions, it uses a 4-point scale, in which the individual evaluates himself/herself in relation to the difficulties felt in performing tasks in the area of health. The Likert scale used consists of the following options: 1-Very easy, 2-Easy, 3-Difficult and 4-Very difficult, and there is also a fifth answer option which corresponds to “Doesn't know/ Doesn't answer”. It integrates there fundamental areas in health: i) health care, ii) health promotion, iii) disease prevention, as well as four levels of information processing: i) access, ii) comprehension, iii) evaluation, iv) use, all of them essential in decision making. Twenty-three issues related to health and health service use, living habits and functional literacy are included. Finally, there are sixteen questions for socio-demographic evaluation of participants. The HLS-EU-PT questionnaire understands LS as interrelated with literacy and involves individual knowledge, motivation and skills in accessing, understanding, evaluating and applying health information. Indeed, it allows the development of critical and decision-making capacity in everyday life and on issues inherent to health care, disease prevention and PS, and consequently the maintenance or improvement of quality of life [7]. The authors have defined cut-off points that limit their levels of health literacy: inadequate $(0$ 25); problematic (25 - 33); sufficient (33 - 42), and this connotation results from the sum of all items divided by their number [8]. The application of the questionnaires was done by direct contact, they were filled in by the main researcher with the users. Two semi-structured interview scripts with open questions were elaborated: i) one directed to the staff with the general objective of identifying the knowledge about DMT2, consisting of eleven open questions, some accom- 
panied by sub-questions on diabetes, healthy eating and food choices, ii) another directed to the professionals responsible for physical activity with the general objective of promoting the physical well-being of the elderly group of the Day Centre, consisting of seven open questions on physical activity and strategies for its promotion. The interviews were conducted by the researcher, recorded on audio support, upon authorization of the interviewees and subsequently fully transcribed. These were carried out in an office, in order to ensure a peaceful and private environment, and took approximately 15 to 20 minutes.

The treatment of the data was descriptive with univariate and bivariate analysis using the Statistical Program for Social Sciences $\left(\right.$ SPSS $^{\circledR}$ ) version 25.0 of Windows and Microsoft ${ }^{\circledR}$ office 2013 tools. Descriptive tables of the sociodemographic characterization and clinical data of the sample were elaborated in study. Subsequently, tables of relationship between the results obtained from the literacy categories and sociodemographic data were also built.

\subsection{Characterization of the Sample and Its Environmental Environment}

It is a group of 22 elderly people from a Day Center in the parish of Arroios, Lisbon (Portugal).

The population of this parish is very heterogeneous due to immigration and for this reason has made it one of the most intercultural areas in Lisbon. The resident of the Arroios mostly come from countries like Brazil, Angola and China. In housing terms, this area is characterized by the predominance of old and dilapidated buildings or those in need of repair and works, although it is currently noted that several restorations have been made in buildings.

Near the Day Center there are educational and commercial establishments as well as public transport (metro, rails). Regarding support from pharmacies, health centers, supermarkets, these goods are accessible, however, a condition for improving access and use. In addition to the satisfaction of the Basic Activities of Daily Living and the Instrumental Activities of Daily Living of the elderly, this Day Center, the responses aimed at this target population aim at the promotion, inclusion and participation in the community, regardless of the greater or lesser degree autonomy/dependency of the elderly and whether they are residing in their home or in an institution.

Regarding the daily transport of these elderly people at various times of the day, the institution provides food and health care, and there may still be a need for home support to ensure food, health or cleaning services. The effort of the organization, namely the health and social professionals who aim to monitor, stimulate and develop skills that allow them to have self-perception of their health and well-being.

\subsection{Sociodemographic Data}

The sample is mostly female (54\%). Regarding age, $91 \%$ of the sample is older than 65 years and an average age of 79 years. Regarding marital status, $46 \%$ are widowed, $9 \%$ separated or divorced and $41 \%$ single. 
Regarding the household, 96\% say they live alone.

The level of educational qualifications is low, most of the elderly (64\%) say they have completed 1 cycle (up to the $4^{\text {th }}$ year) and $36 \%$ do not know how to read or write. All the elderly are retired and the net monthly income of households is low, with $77 \%$ having a monthly income of less than $€ 500$, as shown in Table 1.

\subsection{Low Health Literacy}

It was found that $61.9 \%$ of the elderly have inadequate health literacy, $28.6 \%$ are at the level of problematic health literacy and only $9.5 \%$ reveal a sufficient level of health literacy, as we can see in Table 2. Effectively, the levels of health literacy in our sample are in line with other studies carried out in the Portuguese population in general [18] [19]. The influence of biomedical factors and lifestyles on the onset of these chronic diseases is well defined, and it is only very recently that health literacy has become increasingly important and considered as a determinant of health, due to its relationship with behavioral choices made by

Table 1. Distribution of the sample according to sociodemographic characteristics.

\begin{tabular}{|c|c|c|c|c|}
\hline Variable & Frequency & $\begin{array}{c}\text { Percentage } \\
(\%)\end{array}$ & $\begin{array}{c}\text { Average } \\
\text { age }\end{array}$ & $\begin{array}{l}\text { Standard } \\
\text { deviation }\end{array}$ \\
\hline \multicolumn{5}{|l|}{ Sex } \\
\hline Male & 10 & $45.4 \%$ & & \\
\hline Female & 12 & $54.2 \%$ & & \\
\hline \multicolumn{5}{|l|}{ Ages } \\
\hline 46 - 55 years & 1 & $4.5 \%$ & & \\
\hline $56-56$ years & 1 & $4.5 \%$ & $79.2 \%$ & 11.9 \\
\hline $66-75$ years & 7 & $31.8 \%$ & & \\
\hline over 76 years & 13 & $59.1 \%$ & & \\
\hline \multicolumn{5}{|l|}{ Marital status } \\
\hline Single & 9 & $40.9 \%$ & & \\
\hline Married & 1 & $4.5 \%$ & & \\
\hline Separated/divorced & 2 & $9.1 \%$ & & \\
\hline widower & 10 & $45.5 \%$ & & \\
\hline \multicolumn{5}{|l|}{ Qualifications } \\
\hline Level 0 & 8 & $36.4 \%$ & & \\
\hline Level 1 & 14 & $63.6 \%$ & & \\
\hline \multicolumn{5}{|l|}{ Income } \\
\hline less than 500 & 17 & $77.3 \%$ & & \\
\hline Between $500-800$ & 4 & $18.2 \%$ & & \\
\hline Between $800-1350$ & 1 & $4.5 \%$ & & \\
\hline \multicolumn{5}{|l|}{ Houseshold } \\
\hline Single/live alone & 21 & $95.5 \%$ & & \\
\hline Live together & 1 & $4.5 \%$ & & \\
\hline
\end{tabular}


individuals [20] [21] [31]. Several studies corroborate this idea, demonstrating that low health literacy is related to a perception of low self-efficacy in the prevention and management of diseases [22] [23] [24].

\subsection{Health Literacy and Sociodemographic Data}

When comparing the gender variable with health literacy levels in general, we found that women have lower health literacy levels than men. Still within this variable, the results obtained in different research studies are not consensual: some reveal that men have greater literacy [25] while others reveal the opposite [26] (Table 3).

Due to the confrontation between the age variable and the level of health literacy, we observed that the values of the two variables tend to oscillate in the opposite direction, that is, the levels of health literacy tend to be lower as age advances [27] [28].

Kim [29] also reached results like this one, and the conclusion that individuals over 65 years of age who have inadequate health literacy reveal hypertension and greater limitation in activities of daily living.

Table 2. Literacy levels for the health of the sample.

\begin{tabular}{lccccc}
\hline \multicolumn{2}{c}{ Literacy for general health } & Frequency & Percentage & $\begin{array}{c}\text { Valid } \\
\text { percentage }\end{array}$ & $\begin{array}{c}\text { Cumulative } \\
\text { percentage }\end{array}$ \\
\hline Válid & Inadequate LS & 13 & 59.1 & 61.9 & 61.9 \\
& Problematic LS & 6 & 27.3 & 28.6 & 90.5 \\
& Sufficient LS & 2 & 9.1 & 9.5 & 100.0 \\
& Total & 21 & 95.5 & 100.0 & \\
Omitted & System & 1 & 4.5 & & \\
\cline { 2 - 5 } & Total & 22 & 100.0 & & \\
\hline
\end{tabular}

Table 3. Shows the levels of literacy and sociodemographic data.

\begin{tabular}{cccc}
\hline Variable & Inadequate LS & Problematic LS & Sufficient LS \\
\hline Sex & & & \\
Male (Freq. \%) & $4(30.8 \%)$ & $4(66.7 \%)$ & $2(100 \%)$ \\
Female (Freq \%) & $9(69.2 \%)$ & $2(33.3 \%)$ & $0(0 \%)$ \\
Ages & & & \\
46 - 55 years (Freq. \%) & $0(0 \%)$ & $1(100 \%)$ & $0(0 \%)$ \\
56 - 56 years (Freq. \%) & $1(100 \%)$ & $0(0 \%)$ & $0(0 \%)$ \\
66 - 75 years (Freq. \%) & $4(66.7 \%)$ & $2(33.3 \%)$ & $2(15.4 \%)$ \\
over 76 years (Freq. \%) & $8(61.5 \%)$ & $3(23.1 \%)$ & \\
Qualifications & & & $2(25.0 \%)$ \\
Level 0 (Freq. \%) & $4(50.0 \%)$ & $2(25.0 \%)$ & $0(0 \%)$ \\
Level 1 (Freq. \%) & $9(69.2 \%)$ & $4(30.8 \%)$ & \\
\hline
\end{tabular}




\section{Results and Discussion}

\subsection{Results of Intervention on Well-Being}

Communication and interaction make it possible to improve health literacy levels, have more autonomy and reflect critically on your choices. Effectively, this autonomy-empowerment implies developing decision-making power in individuals in the health-disease process, providing them with the means to promote competent and informed decision-making [30].

For the information to be adequate to the literacy level of the population, particularly the elderly, it must use accessible, assertive, clear and positive language [14].

Health education, therefore, presented itself as the strategy selected by us, since it generates conscious and structured opportunities for learning that involve communication aimed at improving health literacy and equally benefit the knowledge and the development of life skills, which are favorable to the individual and the community.

Therefore, we carry out education sessions in the field of type 2 diabetes mellitus and healthy eating, which is responsible for increasing the quality of life in general, and for the elderly for maintaining their independence and increasing the capacity for the activities of their day-to-day. The results were favorable for the observation, showing access, participation and expressing satisfaction with the options. In effect, these health education sessions aimed to raise awareness and provide the elderly at the Day Center with knowledge and skills that contribute to the adoption of healthy behaviors that contribute to health promotion. Within a broader framework and in the alignment of health systems according to the needs of the elderly, education sessions were also held in the same area for the care providers of this group. We also proceed to the development of partnerships between multidisciplinary teams (nurse instructor of biodanza, nutritionist and nurses from the organization), community and interdisciplinary (USF), in order to continue the intervention developed by us. Despite chronic illness, socioeconomic deprivation, a well-organized organizational structure in the social field allows for a positive investment in the well-being and quality of life of this elderly population.

\subsection{Motivation, Adaptability and Stability}

Motivation for prevention and self-care, particularly in chronic diseases, is essential ([30], p. 331). Therefore, recognizing the beliefs that individuals must then allow them to manage and overcome barriers to action and a better quality of life become crucial, and must be combined with the increase of knowledge and motivation [32]. It is through the activation of these individuals, that it is possible to make them more interested and active in the search for the solution, making them share and transfer this information to others in the group [32].

More than the objective character of a situation, it is necessary to highlight the strength of its subjective impact ([3], p. 4) and "all people are on a line of continuous change between health and illness" (p. 5). For Antonovsky [3], the impact 
of an external situation, such as the economic, political, public health situation of a country or community, is mediated by psychological, social and cultural resources (p. 4) and one of the factors that distinguishes some other people as more resilient, is their ability to adapt as "the biggest key to managing tension" (p. 5). But what allows this same adaptability is the "stability" of the situation (p. 6). This means that stability is knowing what to count on, it is regularity, it is a "sense of coherence" (p. 8) and the prediction of a certain result. We analyzed these results of adaptability, continuity in the experiences we accompany this group of elderly people who attend the day care center of this great social support organization daily. What Antonovsky [3] defends, when changing the paradigm, moving from pathogenesis to salutogenesis, defined by the "global orientation of a diffuse and lasting feeling of confidence, although dynamic, that the stimuli of a person's internal and external environments, in their life cycle, they are structured, predictable and explainable; whereas these resources are available to meet the requirements imposed by these stimuli; that these requirements are challenges worthy of investment and involvement; and that there is a high probability of things going well, as they are reasonably expected ([3], p. 10). Knowing that stressors are always present in human life ([3], p. 10): we see that chronic diseases, limited mobility and scarce resources are not an impediment to a feeling of confidence that in the end everything will run smoothly. compliance, and that gives that stability and at the same time security in recovery. It is this controlled tension that allows, together with self-concept, the control of stress, interpersonal relationships, interactions and relationships with others, bringing what Schalock and Verdugo [33] translate into emotional well-being.

And in the lives of the elderly, social support, carried out by literate organizations, which work in both the social and health domains, as is the case with the organization that welcomes these elderly people that we highlighted in the study as well as affective communication, has wide positive effects in their lives and well-being.

\subsection{The Health Impact of Literate Social Organizations}

Much of the research carried out in the field of Health Literacy has focused on the impact of information provided by the health system and its perception [7]. In order to assess quality of life, well-being as a result of an adequate level of health, it may be necessary to encourage more reflections and studies within social organizations, which are the ones that welcome a high number of elderly people and, within of these, those with health problems, such as the case under analysis of a group of elderly people with diabetes mellitus 2 .

Despite the fact that they have a chronic disease, the individual, relational, social, [34] economic and cultural conditions underlying the determinants of health, clearly influence the daily management of the disease. We found that, while those who have a more intense social activity, travel daily to the day center, have networks of contacts, establish communication with others on a regular 
basis, and thus, having greater adaptability, with relative stability [3] they can consider themselves in "better health" than those who do not have this organized structure of internal and external support.

This social support, which takes into account the access, understanding and use of health-related and also social-related services, with the well-being and quality of life of these needy elderly populations, is made essentially by organizations literate in the field of gerontological social support, which are managed according to personalization, scope, promotion of autonomy and independence, participation, subjective well-being, privacy, social integration, continuity, among others ([35], p. 13).

Kreps [36]: a study carried out with a group of elderly people with Alzheimer's disease in a residential center in the United States, shows how social support, relationships between members, the ability to display their feelings and determining factors for their satisfaction and welfare.

Considering the quality of life of the elderly, Query and Kreps [37], tell us that the Relational Competence Model in Health Communication predicts better results in elderly patients with Alzheimer's disease when caregivers have communication skills and provide social support. This model [37] suggests that the level of competence in communication of health care participants is positively related to the achievement of the desired physiological and psychological results for health.

The Therapeutic or Rehabilitation Model also emphasizes the client's goals versus the goals of the system. It pays attention to skills, but it also analyzes functional deficits, understanding them as barriers to addressing personal goals ([35], p.32).

Considering a set of individual determinants of the elderly population, we can highlight the following:

Competences: The elderly have skills, regardless of the support they need, to develop, to a greater or lesser degree, competent actions.

Well-being: Elderly people must have access to programs that aim to promote health and improve personal well-being (physical, material and emotional), especially when they have significant degrees of commitment and disability, they are entitled to receive support that improves their subjective well-being.

Participation: The elderly has the right to be present in decisions that affect the development of life.

\subsection{The Result: Emotional Well-Being, Which Promotes Quality of Life and Satisfaction}

The emotional well-being of the elderly promotes their quality of life and satisfaction, not only for themselves, but for those who care for them [35] [36] [37].

We can see in Table 4 the difference between the management of a literate organization, oriented towards a person-centered model and the traditional models of organizations. 
Table 4. Differences of models intervention.

\begin{tabular}{|c|c|}
\hline PERSON-CENTERED MODELS & ORGANIZATION-CENTERED MODELS \\
\hline Using a familiar and clear language & Handling clinical language and technicalities \\
\hline Place your focus on person's abilities and skills. & Focus on deficits and needs \\
\hline Macronivel (life plan) interventions & Microlevel intervention (pathologies). \\
\hline Sharing decisions with users, friends, family, professionals. & The decisions depend fundamentally on the professionals. \\
\hline Come to people within your community and usual context & Distance people by emphasizing their differences. \\
\hline Encourage people in the context of social services. & Program planning with a limited number of options. \\
\hline Access people discovering common experiences. & Focus on covering "places" that a service offers. \\
\hline Sketch a desirable lifestyle with an unlimited number of desirable experiences. & Trust in standard interdisciplinary teams. \\
\hline Focus on the quality of life & Dependent work: "I work for those who work directly" \\
\hline Equipment to solve problems (assistive technology) & Organize meetings for professionals. \\
\hline Accountable to those who work directly to make good decisions & Responding to basic needs in the description of the job posts \\
\hline Organize actions in the community to include users, family and workers. & Without creativity and limited to a previously fixed menu. \\
\hline Responding to basic needs in shared responsibilities and commitment & Maintain professional interests. \\
\hline Services can adapt and respond to people. & New initiatives alone can be implemented on a large scale \\
\hline
\end{tabular}

The resources can be distributed to serve the interests of the people.

New initiatives and creativity to find solutions

Source: Adapted from Rodríguez, 2011.

Regarding elderly people, considered by the literature [7] [30] [38] as individuals with lower health literacy, the components of well-being are predictors of their good future decisions.

Schalock and Verdugo [33] emphasize that emotional well-being includes: 1) satisfaction: being satisfied and happy; 2) self-concept: being comfortable with your body, with your way of being, feeling valuable; 3) Absence of stress, having a safe, stable and predictable environment, not feeling nervous, knowing what you can and what you have to do; 4) have interpersonal relationships; 5) having interactions, that is, being with different people, having social networks; 6) having and developing relationships: satisfying, friends and family and living with them. 7) Having support and feeling supported on a physical, emotional, and economic level; 8) Have people to help when it is needed and that they provide information about their behaviors.

\section{Suggestions for the Development of Health Literacy of the Elderly}

A wide range of authors [13] [27] [36] [37] [39] [40] [41] [42] focusing on improving health literacy for older citizens. Health literacy allows, through the development of cognitive and social skills, motivation and greater knowledge, to provide the elderly with better access, understanding and use of the system, and thus a better quality of life, health and well-being, essential to greater satisfaction with life and citizenship. Health literacy is to presuppose a state of evolution in citizenship, of yourself, the older individual and those around you and society.

For this reason, we highlight, in the following points, a set of interventions, 
activities and attitudes that promote this health literacy for older adults, which, together with a set of health determinants, lead to better decisions and, therefore, contributing to a greater well-being in health, at a physiological, psychological, emotional and spiritual level. It is important to invest in:

1) Social and emotional support;

2) Creation of a network of family, group connections with reciprocity ([41], p. 221);

3) Development of psychological well-being;

4) Facilitating access to community health care (primary health care);

5) Deepening of knowledge about significant activities for these older individuals (family visits, group activities; viewing old films; dancing, reading, theater, among others);

6) Better management of emotions related to aging; ([39], p. 295) [42];

7) Assertive, clear and positive (ACP) communication that allows for better effectiveness, understanding of desires and positivity towards the future [13];

8) Age-appropriate nutrition;

9); Physical activity adjusted to capacity and functionality according to age and health status;

10) Reinforcement of subjective well-being, happiness, and gratitude for others and for life and other strengths of character; improving caregivers' communicative skills; [1]

11) Recognition of the positive beliefs and faith of each individual, which allows the reinforcement of their attitudes and maintenance of appropriate behaviors [42];

12) Recognition, respect for your affection and sexual needs;

13) Recognition of the right to your individual affirmation of approval or denial (within and within a normal cognitive framework);

14) The recognition of the importance of urban architecture suitable for the older individual;

15) The strengthening of associations and support organizations for the elderly, whether with health or illness;

16) The evaluation, planning and creation of regulations, legislation appropriate to this profile, as well as to their caregivers;

17) Promotion of the advocacy of older adults, their rights, and duties.

\section{A Path to Solve Problems}

If we consider Kim and Grunig [32] in their problem solving theory, we can assess that the increase in knowledge, the more correct management of beliefs recognized as barriers and the greater involvement allows the individual to have a more proactive attitude, making him more "in search, sorting and transmitting information to others [30]. Not only to retain the information received, but to manage it more effectively, understanding and using it to manage your health risks, in your care and health promotion as well as preventive attitudes of illness. 
According to the Australian Commission on Safety and Quality in Health Care [43] it was necessary to evolve in the concept of health literacy, beyond the fields of public health and health promotion considering that also the environmental issue and social factors influence the Cheers. For this Australian health care commission [43], reductions in health disparities are achieved through greater 1) understanding of the social determinants of health;2) training; 3 ) the involvement of individuals to change health behaviors and practices.

Health literacy is also a result of health education [10] and communication Australian Commission on Safety and Quality in Health Care [43].

It is literate organizations that also make it possible to "bridge" with individuals and communities. These organizations, defined by Brach and others [44], enable a dynamic that promotes the well-being of individuals and communities.

\section{Future Steps}

Reflection on the determinants of health allows us to look holistically at older individuals, inserted in societies that are often not prepared to serve them properly. It is therefore important to have a constructive critical eye on the various dimensions that influence health and that pass through social, economic, cultural, architectural, legislative, communicative, and relational aspects, among others.

\section{Conflicts of Interest}

The authors declare no conflicts of interest regarding the publication of this paper.

\section{References}

[1] Nutbeam, D. (2000) Health Literacy as a Public Goal: A Challenge for Contemporary Health Education and Communication Strategies into the 21st Century. Health Promotion International, 15, 259-267. https://doi.org/10.1093/heapro/15.3.259

[2] Hibbard, J.H., Stockard, J., Mahoney, E.R. and Tusler, M. (2004) Development of the Patient Activation Measure (PAM): Conceptualizing and Measuring Activation in Patients and Consumers. Health Services Research, 39, 1005-1026. https://doi.org/10.1111/j.1475-6773.2004.00269.x

[3] Antonovsky, A. (1985) Health, Stress and Coping. Jossey-Bass, San Francisco.

[4] Faber, M., Bosch, M., Wollersheim, H., Leatherman, S. and Grol, R. (2009) Public Reporting in Health Care: How Do Consumers Use Quality-of-Care Information? A Systematic Review. Medical Care, 47, 1-8. https://doi.org/10.1097/MLR.0b013e3181808bb5

[5] Hibbard, J.H., Peters, E., Dixon, A. and Tusler, M. (2007) Consumer Competencies and the Use of Comparative Quality Information. It Isn't Just about Literacy Medical Care. Research and Review, 64, 379-394. https://doi.org/10.1177/1077558707301630

[6] Kottke, T.E., Stiefel, M. and P. Pronk, N.P. (2016) "Well-Being in All Policies": Promoting Cross-Sectoral Collaboration to Improve People's Lives. Preventing Chronic Disease-Public Health Research, Practice, and Policy, 13, e52. https://doi.org/10.5888/pcd13.160155 
[7] Sørensen, K., Van den Broucke, S., Fullam, J., Doyle, G., Pelikan, J., Slonska, Z. and Brand, H. (2012) Health Literacy and Public Health: A Systematic Review and Integration of Definitions and Models. BMC Public Health, 12, Article No. 80. https://doi.org/10.1186/1471-2458-12-80

[8] Sørensen, K., Pelikan, J.M., Rothlin, F., Ganahl, K., Slonska, Z., Brand, H., et al. (2015) Health Literacy in Europe: Comparative Results of the European Health Literacy Survey (HLS-EU). European Journal of Public Health, 25, 1053-1058. https://doi.org/10.1093/eurpub/ckv043

[9] Quah, S.R. (2008) International Encyclopedia of Public Health. Vol. 3, Academic Press, Cambridge, 204-211.

[10] Zarcadoolas, C., Pleasant, A. and Greer, D.S. (2005) Understanding Health Literacy: An Expanded Model. Health Promotion International, 20, 195-203. https://doi.org/10.1093/heapro/dah609

[11] Bandura, A. (1986) Social Foundations of Thought and Action: A Social Cognitive Theory. Prentice-Hall, Englewood Cliffs.

[12] Damásio, A. (2013) O sentimento de si. Corpo, emoção e consciência. Círculo de Leitores, Lisboa.

[13] Almeida, C.V. (2019) Modelo de comunicação em saúde ACP: As competências de comunicação no cerne de uma literacia em saúde transversal, holística e prática. In: Lopes, C. and Almeida, C.V., Eds., Literacia em saúde na prática, Edições ISPA, Lisboa, 43-52.

http://repositorio.ispa.pt/bitstream/10400.12/7305/5/Literacia\%20da\%20Sa\%C3\%B Ade\%20na\%20Pr\%C3\%A1tica\%20\%28E-Book\%29.pdf

[14] DGS (2019) Manual de Boas Práticas Literacia em Saúde: Capacitação dos Profissionais de Saúde. Direção de Serviços de Prevenção da Doença e Promoção da Saúde, Lisboa. (proposta da ideia e principal autora)

[15] Paasche-Orlow, M.K. and Wolf, M.S. (2007) The Causal Pathways Linking Health Literacy to Health Outcomes. American Journal of Health Behavior, 31, 19-26. https://doi.org/10.5993/AJHB.31.s1.4

[16] Ad Hoc Committee on Health Literacy for the Council on Scientific Affairs (1999) Health Literacy (Report of the Council on Scientific Affairs). JAMA, 281, 552-557. https://doi.org/10.1001/jama.281.6.552

[17] WHO (2014) Health in All Policies: Helsinki Statement. Framework for Country Action. The Author. http://www.euro.who.int/_data/assets/pdf_file/0004/74704/E82997.pdf?ua=1

[18] Pedro, A.R., Amaral, O. and Escoval, A. (2016) Literacia em saúde, dos dados à ação: Tradução, validação e aplicação do European Health Literacy Survey em Portugal. Revista Portuguesa de Saúde Publica, 34, 259-275. https://doi.org/10.1016/j.rpsp.2016.07.002

[19] Saboga-Nunes, L. (2014) Literacia para a saúde e a conscientização da cidadania positiva. Revista de Enfermagem Referência, 3, 94-99.

[20] Davey, J., Holden, C. and Smith, B. (2015) The Correlates of Chronic Disease-Related Health Literacy and Its Components among Men: A Systematic Review. BMC Public Health, 15, Article No. 589. https://doi.org/10.1186/s12889-015-1900-5

[21] Panagioti, M., Skevington, S., Hann, M., Kelly, H., Blakemore, A., Reeves, D. and Bower, P. (2018) Effect of Literacy on the Quality of Life of Older Patients with Long-Term Conditions: A Large Cohort Study in UK General Practice. Quality of Life Research, 27, 1257-1268. https://doi.org/10.1007/s11136-017-1775-2

[22] Cavanaugh, K. (2011) Health Literacy in Diabetes Care: Explanation, Evidence and 
Equipment. Diabetes Management (London), 1, 191-199. https://doi.org/10.2217/dmt.11.5

[23] White, R., Wolff, K., Cavanaugh, K. and Rothman, R. (2010) Addressing Health Literacy and Numeracy to Improve Diabetes Education and Care. Diabetes Spectrum, 23, 238-243. https://doi.org/10.2337/diaspect.23.4.238

[24] Santos, O. (2010) O papel da Literacia em saúde: Capacitando a pessoa com excesso de peso para o control e redução da carga ponderal. Observatório Nacional da $O b$ esidade e do control do Peso, 4, 127-134.

https://dspace.uevora.pt/rdpc/bitstream/10174/2320/1/(2010)\%20Literacia\%20em\% 20saúde\%20-\%20capacitando\%20a\%20pessoa\%20com $\% 20$ excesso $\% 20$ de $\% 20$ peso $\%$ 20para $\% 20 \mathrm{o} \% 20$ controlo $\% 20 \mathrm{e} \% 20$ redução $\% 20 \mathrm{da} \% 20$ carga $\% 20$ ponderal.pdf

[25] Toçi, E., et al. (2013) Health Literacy and Socioeconomic Characteristics among Older People in Transitional Kosovo. British Journal of Medicine and Medical Research, 3, 1646-1658. https://doi.org/10.9734/BJMMR/2013/3972

[26] Sudore, R., et al. (2006) Limited Literacy in Old People and Disparities in Health and Healthcare Access. Journal of the American Geriatrics Society, 54, 770-776. https://doi.org/10.1111/j.1532-5415.2006.00691.x

[27] Serrão, C., Veiga, S. and Vieira, I. (2015) Literacia em saúde: Resultados obtidos a partir de uma amostra de pessoa idosas portuguesas. Revista Portuguesa de Enfermagem de Saúde Mental, 2, 33-38. https://doi.org/10.19131/jpmhn.0006 http://www.scielo.mec.pt/pdf/rpesm/nspe2/nspe2a06.pdf

[28] Gazmararian, J.A., Wolf, M.S. and Baker, D.W. (2005) Health Literacy and Functional Health Status among Older Adults. Archives of Internal Medicine, 165, 19461947. https://doi.org/10.1001/archinte.165.17.1946

[29] Kim, S. (2009) Health Literacy and Functional Health Status in Korean Old Adults. Journal of Clinical Nursing, 18, 2337-2343. https://doi.org/10.1111/j.1365-2702.2008.02739.x

[30] Veiga, A. and Vaz de Almeida, C. (2020) Problem-Solving in Prevention of Type 2 Diabetes Mellitus in Older People. Patient Safety and Quality Health Care.

[31] Rosenstock, I.M. (1974) Historical Origins of the Health Belief Model. Health Education Monographs, 2, 328-335. https://doi.org/10.1177/109019817400200403

[32] Kim, J.-N. and Grunig, J.E. (2011) Problem Solving and Communicative Action: A Situational Theory of Problem Solving. Journal of Communication, 61, 120-149. https://doi.org/10.1111/j.1460-2466.2010.01529.x

[33] Schalock, R.L. and Verdugo Alonso, M.A.V. (2002) Handbook on Quality of Life for Human Service Practitioners. AAMR American Association on Mental Retardation, Washington DC.

[34] Kreps, G.L. (2009) Applying Weick's Model of Organizing to Healthcare and Health Promotion: Highlighting the Central Role of Health Communication. Patient Education and Counseling, 74, 347-355. https://doi.org/10.1016/j.pec.2008.12.002

[35] Rodríguez, T.M. (2011) La atención gerontológica centrada en la persona. Guía para la intervención profesional En los centros y servicios de atención a personas Mayores en situación de fragilidad o dependência. Servicio Central de Publicaciones del Gobierno Vasco, San Sebastián.

[36] Kreps, G.L. (1996) Promoting a Consumer Orientation to Healthcare and Health Promotion. Journal of Health Psychology, 1, 41-48.

https://doi.org/10.1177/135910539600100104

[37] Query, J.L. and Kreps, G.L. (1996) Testing a Relational Model for Health Commu- 
nication Competence among Caregivers for Individuals with Alzheimer's Disease. Journal of Health Psychology, 1, 335-351. https://doi.org/10.1177/135910539600100307

[38] Espanha, R., Avila, P. and Mendes, R.M. (2016) A literacia em saúde em Portugal. Fundação Calouste Gulbenkian, Lisboa.

[39] Street, R.L., O’Malley, K.J., Cooper, L.A. and Haidet, P. (2008) Understanding Concordance in Patient-Physician Relationships: Personal and Ethnic Dimensions of Shared Identity. Annals Family Medicine, 6, 198-205. https://doi.org/10.1370/afm.821

[40] Teixeira, J.A.C. (2004) Comunicação em saúde: Relação técnicos de saúde-utentes. Análise Psicológica, 22, 615-620.

http://www.scielo.mec.pt/scielo.php?script=sci_arttext\&pid=S0870-8231200400030 0021

[41] Viswanath, K. (2006) Public Communications and Its Role in Reducing and Eliminating Health Disparities. In: Thomson, G.E., Mitchell, F. and Williams, M.B., Eds., Examining the Health Disparities Research Plan of the National Institutes of Health: Unfinished Business, National Academies Press, Washington DC, 215-253.

[42] Seligman, M.E.P., Steen, T.A., Park, N. and Peterson, C. (2005) Positive Psychology Progress: Empirical Validation of Interventions. American Psychologist, 60, 410-421. https://doi.org/10.1037/0003-066X.60.5.410

[43] Australian Commission on Safety and Quality in Health Care (2014) Health Literacy: Taking Action to Improve Safety and Quality. ACSQHC, Sydney.

[44] Brach, C., Keller, D., Hernandez, L.M., Bauer, C., Parker, R., Dreyer, B., Schyve, P., Lemerise, A.J. and Schillinger, D. (2012) Ten Attributes of Health Literate Health Care Organizations. 